\title{
Psychrobacter piechaudii shunt infection: first report of human infection
}

\author{
Ashwin Kumaria ${ }^{1}$ (I) . Shanika A. Crusz ${ }^{2} \cdot$ Michelle Lister $^{2} \cdot$ Matthew A. Kirkman ${ }^{1}$ - Donald C. Macarthur ${ }^{2}$
}

Received: 14 May 2021 / Accepted: 23 October 2021 / Published online: 28 October 2021

(c) The Author(s), under exclusive licence to Springer-Verlag GmbH Germany, part of Springer Nature 2021

\begin{abstract}
Psychrobacter piechaudii is a recently described species of Gram-negative bacteria in the Moraxellaceae family. No cases of human infection due to this species have been described before. We report the case of an ex-premature infant girl with hydrocephalus secondary to intraventricular haemorrhage who underwent multiple cerebrospinal fluid (CSF) shunt operations. She ultimately developed Psychrobacter piechaudii meningitis, presenting as ventriculoperitoneal shunt dysfunction and wound leak, which necessitated removal of the shunt, a period of external ventricular drainage and antibiotics. We found this organism to be sensitive to intravenous ceftazidime $(50 \mathrm{mg} / \mathrm{kg})$ and ciprofloxacin, and a 7-10 day treatment course prior to shunt re-insertion (and 3 week total course) was sufficient. The patient is well post-operatively. To the best of our knowledge, this is the first reported case of Psychrobacter piechaudii infection in a human.
\end{abstract}

Keywords Psychrobacter piechaudii $\cdot$ Shunt infection $\cdot$ Hydrocephalus

\section{Case report}

An ex-premature infant girl was referred to our tertiary neurosurgical centre with concerns of an enlarging head circumference. One of two monochorionic diamniotic twins, she had been born at 29 weeks +4 by emergency caesarean section following reduced foetal movement and concerning features on cardiotocography. Respiratory distress at birth necessitated endotracheal intubation and continuous positive pressure ventilation for one day and non-invasive oxygen therapy for 4 days. Prenatally, she had been diagnosed with ascites and twin-to-twin transfusion syndrome. She had a patent foramen ovale that was managed conservatively and had also been treated for chronic lung disease at 28 days of age.

Cranial ultrasound scan demonstrated hydrocephalus secondary to Papile Grade IV intraventricular and intraparenchymal haemorrhage and this was confirmed on subsequent MRI (Fig. 1). An anterior fontanelle tap was performed as

Ashwin Kumaria

Ashwin.Kumaria@doctors.org.uk

1 Department of Paediatric Neurosurgery, Queen's Medical Centre, Derby Road, Nottingham NG7 2UH, UK

2 Department of Clinical Microbiology, Queen's Medical Centre, Nottingham, UK

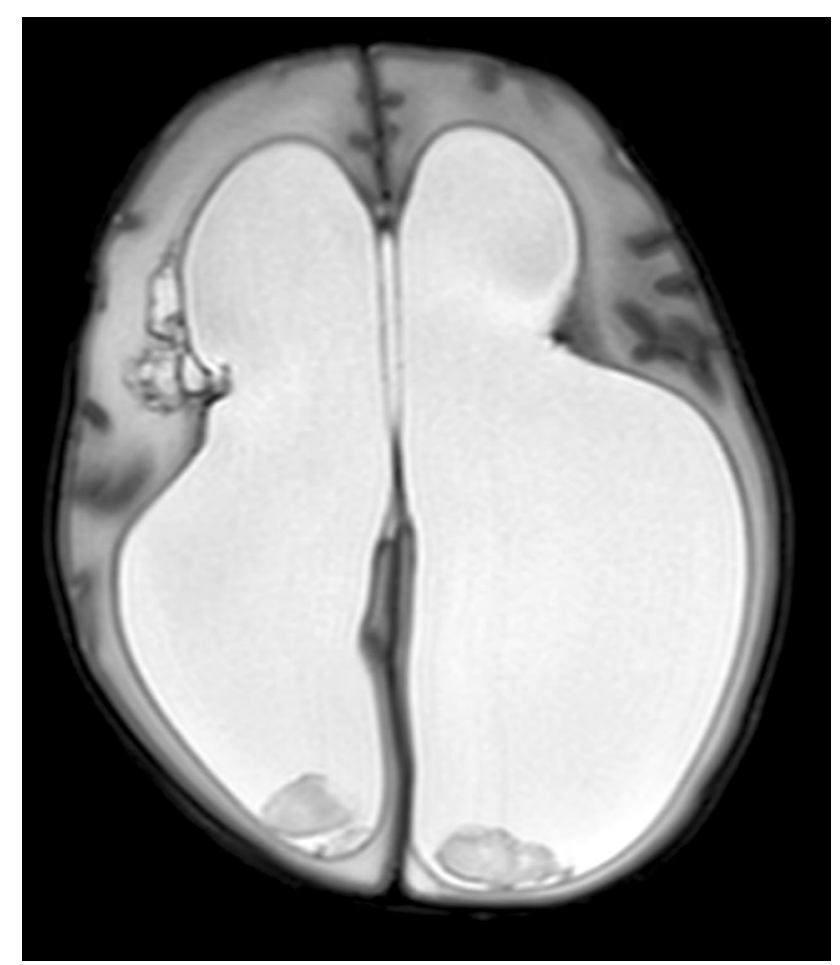

Fig. 1 Axial T2-weighted MRI demonstrating hydrocephalus secondary to Papile Grade IV intraventricular and intraparenchymal haemorrhage 
part of a workup for cerebrospinal fluid (CSF) diversion, which did not reveal any evidence of infection. She underwent left parietal ventriculoperitoneal (VP) shunt insertion aged 4 weeks (age corrected for prematurity). Three weeks later, she developed non-infectious mechanical shunt dysfunction necessitating re-siting of the ventricular catheter.

She was readmitted three weeks later with shunt dysfunction presenting as a rapidly increasing head circumference associated with vomiting. On examination, there was no fever (temperature $37.4{ }^{\circ} \mathrm{C}$ ), she appeared irritable but there was no meningismus and she was tachycardic (heart rate 166), tachypnoeic (respiratory rate 53) and hypertensive $(108 / 58 \mathrm{mmHg})$. Accordingly, she underwent emergency removal of her previous shunt and insertion of a temporary external ventricular drain (EVD).

Microbiological examination revealed no organisms in the Gram stain for either CSF or subdural fluid. However, scanty growth of a Gram-negative coccobacillus was identified after $48 \mathrm{~h}$ on blood agar and chocolate agar in $\mathrm{CO}_{2}$ at $37{ }^{\circ} \mathrm{C}$ in both samples. Initial identification of the organism was performed by matrix-assisted laser desorption ionization-time of flight mass spectrometry (MALDITOF) (Bruker Daltonik S. A., Wissembourg, France) using FlexControl software (version 3.0) in triplicate. The organism identified as Psychrobacter sanguinis with a score of 1.81, 1.72 and 1.71. A score between 1.7 and 1.9 indicates genus identification only. Sequencing of the 16S rRNA gene was performed using the universal primers $314 \mathrm{~F}$ (5'-CCTACGGGAGGCAGCAG-3') and 1195R (5'-GAC GTCRTCCNCDCCTTCCTC-3') resulting in a fragment $753 \mathrm{bp}$ in length. The sequence was analysed using EzBiocloud [1] and NCBI BLAST resulting in $99.3 \%$ and $99.6 \%$ identity, respectively, with Psychrobacter piechaudii type strain (GenBank Accession NR_157980.1). Phylogenetic analysis was performed using leBIBI [2] which identified $P$. piechaudii as the closest sequence based on patristic distance. This isolate was shown to be sensitive to ceftazidime, ciprofloxacin and meropenem.

A 7- to 10-day course of intravenous ceftazidime $(50 \mathrm{mg} /$ $\mathrm{kg}$ ) was planned prior to shunt reinsertion. CSF taken at $48 \mathrm{~h}$ prior to planned VP shunt reinsertion was sterile. MRI imaging did not demonstrate evidence of empyema or cerebritis, and she had improved clinically. Therefore, she underwent VP shunt insertion with single doses of teicoplanin and gentamicin at induction and has remained well since, completing a total 3 weeks course of oral ciprofloxacin.

\section{Discussion}

Psychrobacter piechaudii is a recently described bacterium characterised at the Institut Pasteur in Paris in 2017 [3]. The Psychrobacter genus is part of the family Moraxellaceae, whose other genera include Moraxella and Acinetobacter. Psychrobacter was described as a novel genus in 1986, whose characteristics include aerobic, Gram-negative, non-motile, coccobacilli which are psychrophilic - i.e. extremophilic organisms capable of growth and reproduction at temperatures less than $10^{\circ} \mathrm{C}$. At the time of writing, 57 species of Psychrobacter have been described (Fig. 2). Owing to extremophilic characteristics, Psychrobacter has been typically associated with Antarctic and marine environments.

Human infection due to Psychrobacter is extremely rare. A wound infection associated with oceanic/marine environment exposure has been attributed to $P$. sanguinis [4]. $P$. phenylpyruvicus bacteraemia has been reported following consumption of raw shellfish [5]. Nonetheless, most other human Psychrobacter infections have been deemed opportunistic, including $P$. arenosus bacteraemia following blood transfusion [6], nosocomial $P$. immobilis ocular infection [7] and $P$. phenylpyruvicus surgical wound infection [8]. Three cases of Psychrobacter associated meningitis have been described, including two in infant/paediatric patients [9] and one in a patient with post-haemorrhagic hydrocephalus treated with insertion of an EVD [10].

To the best of our knowledge, this is the first report of a human infection with $P$. piechaudii, noting recent increased routine application of technologies to identify and speciate organisms, which may previously have simply been described as "environmental Gram negatives." It is also only the fourth Psychrobacter infection of the central nervous system. Our case is being treated as nosocomial, the patient having spent virtually her entire life in hospital.

Of note, this episode took place during the COVID-19 pandemic, which is ongoing at the time of writing. During this time, we have been taking the utmost infection control precautions including mandatory facemasks, rigorous hand hygiene and limited visitors in hospital among many others. Although these measures were instituted to curtail the SARS-CoV-2 virus, it is possible that bacterial colonisation and the skin or gut microbiome evolved accordingly, with further selection pressures exerted by prior antibiotic use. It is likely that this organism forms biofilms on prosthetic material; therefore, implant removal is a key aspect of management.

Prior to the confirmed Psychrobacter piechaudii infection, our patient underwent three interventions or access procedures to CSF spaces - one anterior fontanelle tap and two VP shunt insertions. Following the results of the landmark BASICS trial [11], we have implemented antibiotic impregnated shunt tubing as standard, including in this case. Although we have since seen a decline in Grampositive shunt-related infections, Gram-negative infections such as this one continue to occur. Fortunately, the organism was sensitive to a number of agents, including ceftazidime, ciprofloxacin and meropenem and the patient 


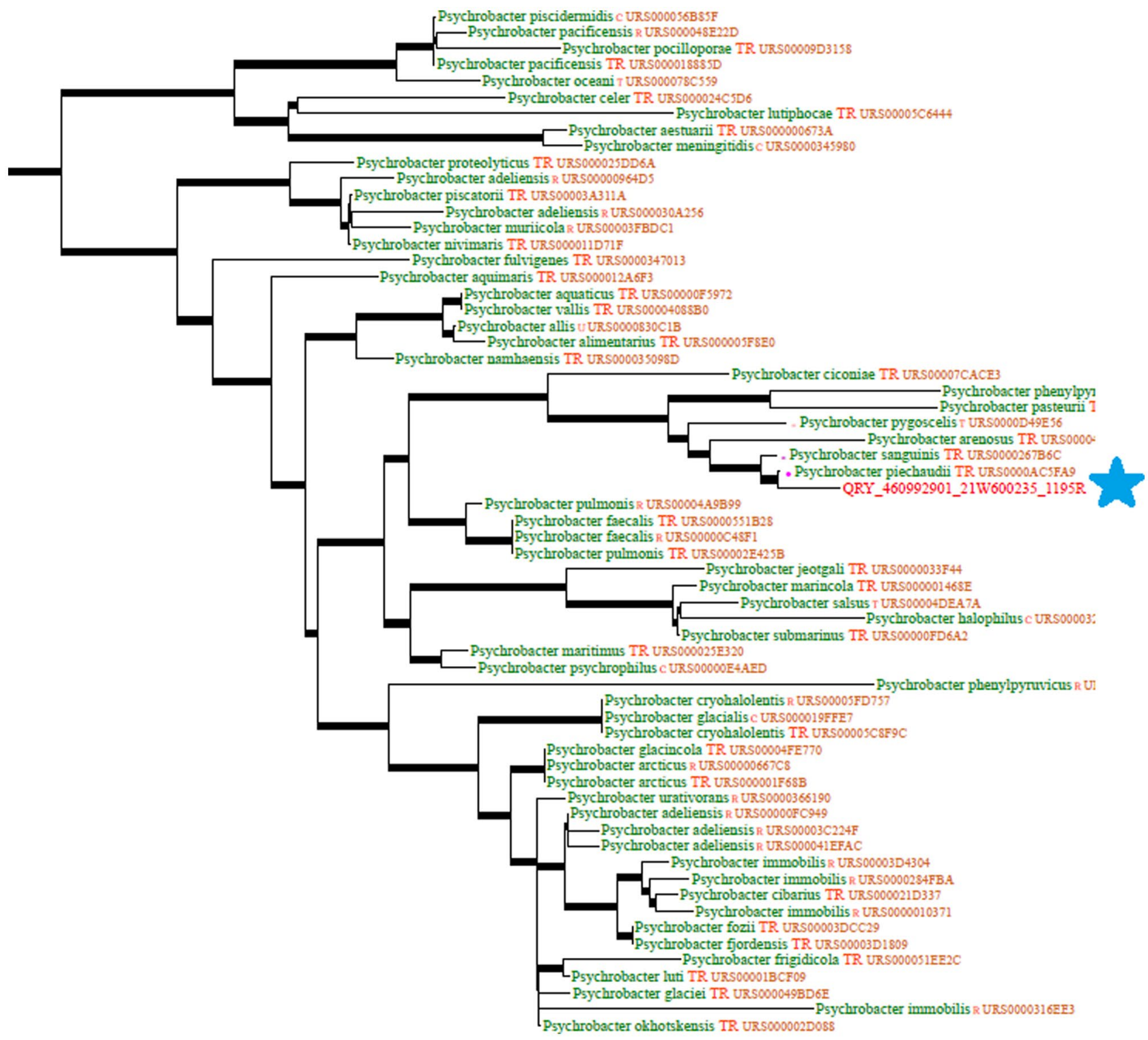

Fig. 2 Phylogenetic tree of Psychrobacter genus based on genetic sequences. The organism isolated is highlighted with a star

has done well following removal of the infected prosthetic material, a course of systemic antibiotics and VP shunt re-implantation.

\section{Declarations}

Consent The patient's parents provided consent for this case to be published and/or presented, including anonymised use of radiological images.

Conflict of interest The authors declare that they have no conflict of interest.

\section{References}

1. Yoon SH, Ha SM, Kwon S, Lim J, Kim Y, Seo H, Chun J (2017) Introducing EzBioCloud: a taxonomically united database of 16S rRNA and whole genome assemblies. Int J Syst Evol Microbiol 67:1613-1617

2. Flandrois J-P, Perrière G, Gouy M (2015) leBIBIQBPP: A set of databases and a webtool for automatic phylogenetic analysis of prokaryotic sequences. BMC Bioinformatics 16:251. https://doi. org/10.1186/s12859-015-0692-Z

3. Hurtado-Ortiz R, Nazimoudine A, Criscuolo A, Hugon P, Mornico D, Brisse S, Bizet C, Clermont D (2017) Psychrobacter pasteurii and Psychrobacter piechaudii sp. nov., two novel species within the genus Psychrobacter. Int J Syst Evol Microbiol 67(9):31923197. https://doi.org/10.1099/ijsem.0.002065. Epub 25 Aug 2017 PMID: 28840795 
4. Bonwitt J, Tran M, Droz A, Gonzalez A, Glover WA (2018) Psychrobacter sanguinis wound infection associated with marine environment exposure, Washington, USA. Emerg Infect Dis 24(10):1942-1944. https://doi.org/10.3201/eid2410.171821. PMID: 30226173; PMCID: PMC6154140

5. Leung WK, Chow VC, Chan MC, Ling JM, Sung JJ (2006) Psychrobacter bacteraemia in a cirrhotic patient after the consumption of raw geoduck clam. J Infect 52(6):e169-e171. https:// doi.org/10.1016/j.jinf.2005.08.031. Epub 25 Oct 2005 PMID: 16253331

6. Caspar Y, Recule C, Pouzol P, Lafeuillade B, Mallaret MR, Maurin M, Croize J (2013) Psychrobacter arenosus bacteremia after blood transfusion. France Emerg Infect Dis 19(7):11181120. https://doi.org/10.3201/eid1907.121599. PMID: 23764120; PMCID: PMC3713977

7. Gini GA (1990) Ocular infection caused by Psychrobacter immobilis acquired in the hospital. J Clin Microbiol 28(2):400401. https://doi.org/10.1128/JCM.28.2.400-401.1990. PMID: 2312690; PMCID: PMC269623

8. Stepanović S, Vuković D, Bedora-Faure M, K'ouas G, Djukić S, Svabić-Vlahović M, Carlier JP (2007) Surgical wound infection associated with Psychrobacter phenylpyruvicus-like organism. Diagn Microbiol Infect Dis 57(2):217-219. https://doi.org/ 10.1016/j.diagmicrobio.2006.08.002. Epub 20 Sep 2006 PMID: 16989971

9. Lloyd-Puryear M, Wallace D, Baldwin T, Hollis DG (1991) Meningitis caused by Psychrobacter immobilis in an infant. J Clin Microbiol 29(9):2041-2042. https://doi.org/10.1128/JCM.29.9. 2041-2042.1991. PMID: 1774332; PMCID: PMC270256

10. Le Guern R, Wallet F, Vega E, Courcol RJ, Loïez C (2014) Psychrobacter sanguinis: an unusual bacterium for nosocomial meningitis. J Clin Microbiol 52(9):3475-7. https://doi.org/10.1128/ JCM.01197-14. Epub 2 Jul 2014. PMID: 24989605; PMCID: PMC4313189

11. Mallucci CL, Jenkinson MD, Conroy EJ, Hartley JC, Brown M, Dalton J et al (2019) BASICS Study collaborators. Antibiotic or silver versus standard ventriculoperitoneal shunts (BASICS): a multicentre, single-blinded, randomised trial and economic evaluation. Lancet 26;394(10208):1530-1539. https://doi.org/10.1016/ S0140-6736(19)31603-4. Epub 12 Sep 2019. Erratum in: Lancet. 18 Sep 2019; Erratum in: Lancet 395(10240):1834. PMID: 31522843; PMCID: PMC6999649

Publisher's Note Springer Nature remains neutral with regard to jurisdictional claims in published maps and institutional affiliations. 